Int. J. Electrochem. Sci., 12 (2017) $4630-4639$

Short Communication

\title{
A Electrochemical Performance Analysis of High and Low Pt Loading in Pt/C Catalysts by Rotating Disk Electrode
}

\author{
Yan Rao ${ }^{1,2}$, Fen $\mathrm{Zhou}^{1,2}$, Kailin Fu ${ }^{1,2}$, Wei Guo ${ }^{1,2, *}$, Mu Pan ${ }^{1,2, *}$ \\ ${ }^{1}$ State Key Laboratory of Advanced Technology for Materials Synthesis and Processing, Wuhan \\ University of Technology, Luoshi Road 122\#, Wuhan 430070, PR China \\ ${ }^{2}$ Hubei Key Laboratory of Fuel Cells, Wuhan University of Technology, Luoshi Road 122\#, Wuhan \\ 430070, PR China \\ *E-mail:weiguo2016@whut.edu.cn,panmu@whut.edu.cn
}

doi: $10.20964 / 2017.06 .91$

Received: 17 March 2017 / Accepted: 19 April 2017 / Published: 12 May 2017

A series of Pt/C catalyst electrodes with different Pt loadings ranging from $12 \mu \mathrm{g} / \mathrm{cm}^{2}$ to $400 \mu \mathrm{g} / \mathrm{cm}^{2}$ was characterized in our experiments by rotational disk electrode (RDE) system. The influence of Pt loading on the performance of the catalyst was systematically analyzed. We found that if the Pt loading was very low, which the electrode thickness could be neglected, the $\mathrm{H}^{+}$in solution can be quickly penetrated into the electrode, the impact of mass transfer can be ignored and the electrochemical active area (ECSA) was equal to the inherent value; when the electrode thickness increases gradually with the increasing Pt loading, the mass transfer gets restricted as well as ohm potential drop in the solution, the electrode potential was to shift significantly as a result, and the ECSA was lower than the inherent value. Oxygen reduction reaction (ORR) performance also verified this point. The content of effective Pt loading in high Pt loading electrode $\left(>100 \mu \mathrm{g} / \mathrm{cm}^{2}\right.$, or electrode thickness $\left.>2.17 \mu \mathrm{m}\right)$ can be calculated by the ratio of ECSA for high to low Pt loading.

Keywords: Rotating disk electrode, Pt/C catalyst, Pt loading, Electrochemical active area, Oxygen reduction reaction

\section{$\underline{\text { FULL TEXT }}$}

(C) 2017 The Authors. Published by ESG (www.electrochemsci.org). This article is an open access article distributed under the terms and conditions of the Creative Commons Attribution license (http://creativecommons.org/licenses/by/4.0/). 